Case Report

\title{
Congenital Syndactyly of the Fingers : A Report of Two Cases
}

\section{Sanath Kumar Shetty ${ }^{1}$, Anoop Hegde', Lawrence John Mathias ${ }^{3} \&$ H. Ravindranath Rai ${ }^{4}$ \\ ${ }^{1}$ Assistant Professor, ${ }^{2}$ Postgraduate, ${ }^{3}$ Professor, ${ }^{4}$ Professor \& HOD,}

Department of Orthopaedic Surgery, K.S. Hegde M edical Academy, Nitte University, M angalore, Karnataka, India.

\author{
Correspondence \\ Sanath Kumar Shetty \\ Assistant Professor, Department of Orthopaedic Surgery, K.S. Hegde M edical Academy, \\ Nitte University, M angalore - 575 018, Karnataka, India. \\ Mobile : +91 9845069383 E-mail : sanathkumarshetty@ hotmail.com
}

\begin{abstract}
Syndactyly is defined as the failure of separation of the digits during early gestation. It is one of the most common congenital anomalies. The incidence of syndactyly is uncertain, but estimates range from 1 in 2,500 live births. During development, the fingers are webbed. This remains so, until apoptosis and skin recession allow for formation of the digital interspaces. Full inter-digital spaces are usually present by the end of the 6 th week of gestation.

Here we present two patients and three hands who presented to us with syndactyly of the fingers. The first patient who was a 13 year old girl, had complete complex syndactyly between the ring and middle fingers of both hands. She underwent complete release with full thickness skin grafting in the first sitting. Six weeks later, she was reviewed and was noted to have developed scar contracture of the middle finger for which she underwent contracture release and z-plasty as a secondary procedure. In the final review at four months after the second surgery, the child was noted to have only terminal restriction of movements of the involved fingers of both hands with 'fair results' (as per the criteria of Cortez et al).

The second patient was a two years old boy, who presented to us with incomplete simple syndactyly of the ring and index finger of the left hand. He was managed with percutaneous release of the syndactyly. He was reviewed after 4 months and there was full range of movement of the involved digits. He was also noted to have 'fair results' (as per the criteria of Cortezet al).

As we had two different cases with a heterogenous presentation of two different types of syndactyly and who underwent different modalities of management, we are presenting it as an interesting case report in our article.
\end{abstract}

Key words: Webbing, reperfusion abnormality, Apert's syndrome, congenital hand anamoly.

\section{Introduction}

Syndactyly is the second commonest congenital hand anomaly and occurs in about 1:2500 live births, more commonly in males, and is most often seen in the third web space $^{1}$. The condition has a strong familial tendency and is usually bilateral in presentation. It can be either primary or secondary, the former being due to a failure of differentiation or separation. Secondary syndactyly is a result of antecedent events and is produced by refusion

\begin{tabular}{|c|}
\hline Access this article online \\
\hline Quick Response Code \\
\hline
\end{tabular}
abnormality ${ }^{2}$. Syndactyly may present as the sole abnormality or may be associated with other syndromes like Poland's, Cleft hand or Apert's $s^{1}$. The anomaly can also be classified as either complete or incomplete, depending on the extent of fusion of adjacent digits. Complete syndactyly is the type where the fingers are joined from the web to the tip. Incomplete syndactyly denotes a type where the fusion of the web spaces occurs only at a point between the web and the tip. Simple syndactyly defines a subtype in which only the skin is involved while complex syndactyly involves bone, the neurovascular bundle and nail structure. ${ }^{3}$

\section{Case report}

A 13 year old girl presented to us with complaints of deformity of both hands since birth. Clinical and radiological evaluation suggested a complete complex syndactyly between middle and ring finger of both hands [Figures 1(A), 1(B)]. Radiographs revealed a bony fusion between the terminal phalanges of the middle and ring fingers [Fingers 2(A), 2(B)]. A complete clinical evaluation 
showed no association with any syndrome or any underlying systemic disease.

She underwent a complete bony release with secondary skin grafting as a primary procedure. Six weeks later she was reviewed and was noted to have a scar contracture [Figure 3] with restriction of finger movements. Z-platy was performed and scar contracture release was done as a secondary procedure. Four months after the second surgery she was reviewed and she was noted to have acceptable range of motion of all the digits and she was able to do all daily activities comfortably with 'fair results' as per the criteria of Cortez et al. ${ }^{4}$ No other complications were noted.

The second case was of a two year old male child, who presented with complaints of deformity of the left hand since birth. Clinical and radiological evaluation led us to a diagnosis of a simple type of syndactyly between the index and ring finger of left hand [Figure 4 (A), 4(B)]. Clinical

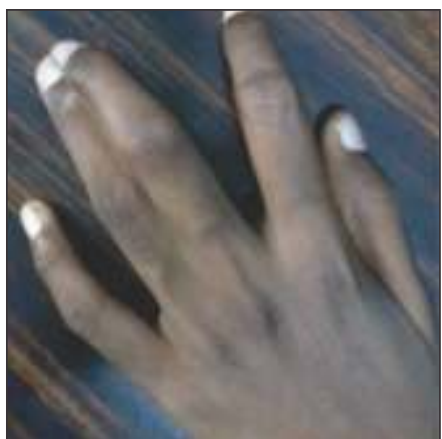

Fig. 1 (A)

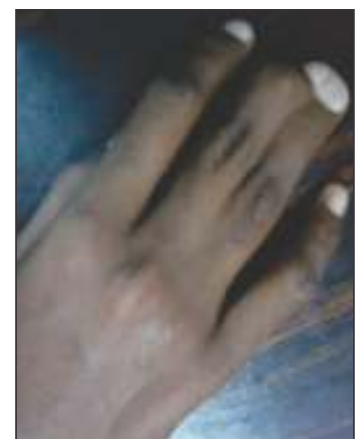

Fig. 1 (B)
Fig. 1(A) and 1(B) : Image showing complete and complex syndactyly between the $3^{\text {rd }}$ and $4^{\text {th }}$ digits of both hands

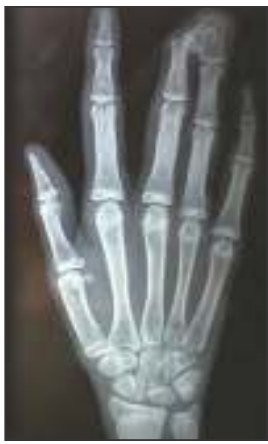

Fig. 2 (A)

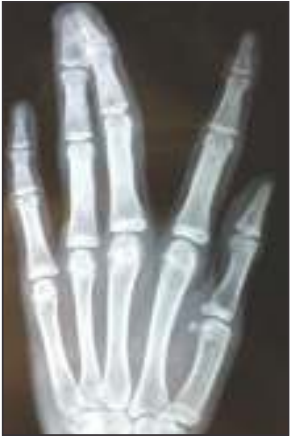

Fig. 2 (B)
Fig. 2(A) and 2(B): AP views of both hands showing bony fusion of terminal phalanx of both ring and middle fingers of both hands (Complextype of syndactyly). assessment and detailed evaluation showed no association with any systemic illness or association with any syndrome.

He underwent a percutaneous release of the syndactyly with a zig-zag incision. He was followed up at regular intervals and during the final follow up after 4 months of surgery, he was noted to have full range of motion of the digits with an acceptable hand function [Figure 5]. He was noted to have 'fair results' as per the criteria of Cortez et al. ${ }^{4}$ No complications were noted.

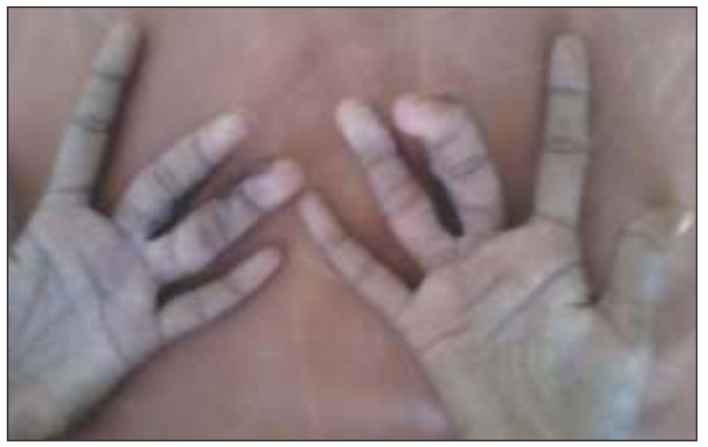

Fig. 3 : After the primary syndactyly release of both hands. Note the flexion contracture of right middle finger at distal interphalangeal joint with malrotation in ringht middle and left ring finger.

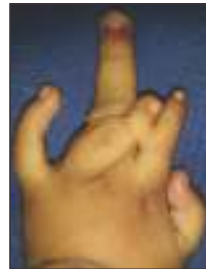

Fig. 4 (A)

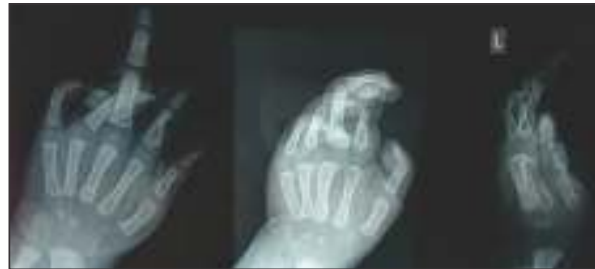

Fig. 4 (B)
Fig. 4(A): Simple incomplete syndactyly of left hand between indexand ring fingers.

Fig. 4(B): AP, Lateral and oblique views of the left hand showing no bony fusion between index and ring fingers confirming a simple type of syndactyly.

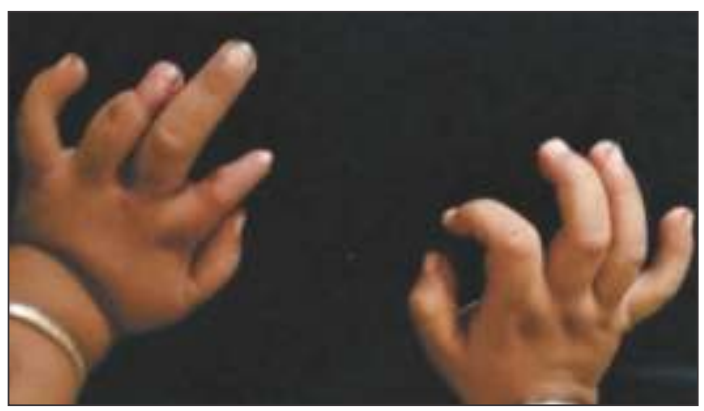

Fig. 5 : After surgical release of syndactyly. Note the left hand is nearly similar to the digits of the right hand after release. 


\section{Discussion}

Most published studies regarding the surgical reconstruction of syndactyly include heterogeneous populations of patients with simple, complex, and complicated syndactyly. Previous authors have noted that complex syndactyly has poorer outcomes with worse function, increased finger deformity, and a higher rate of revision surgery. ${ }^{5,6,7,8}$ The purpose of this investigation was to evaluate a homogeneous group of complete, complex syndactyly patients, using both objective and subjective outcome measures, in an effort to better understand the specific challenges of reconstruction.

The aim of treatment in syndactyly is to separate the fused digits, provide cutaneous cover and create a normal web space. In the past, there have been numerous techniques described for syndactyly correction. The methods have differed in respect of separation of the digits and reconstruction of the web space. It is accepted that longterm stability of the newly created web space is best achieved when the web space is reconstructed using a flap. ${ }^{9}$

Traditional surgical approaches to syndactyly repair have used flaps from the dorsum of the involved fingers and dorsal and palmar interdigitating flaps. Surgical correction of syndactyly needs to be simple and have a minimal rate of secondary correction. ${ }^{10,11,12}$

\section{References}

1. N.J. Percival, P.J. Sykes. Syndactyly: a review of the factors which influence surgical treatment J Hand Surg (Br), 14B (1989), pp. 96-200.

2. M.A. Entin. Syndactyly of upper limb-morphogenesis, classification and management Clin Plast Surg, 3 (1976), pp. 129-140.

3. Jobe M.T. Congenital anamolies of the hand. Campbell's Operative Orthopaedics. Twelfth Edition. Volume IV. 2013. Chapter 79. pp 37463747.

4. Cortez. M, Fernandes Júnior V.J, Da Silva R.F, Gilbert A, Valenti P, Brandt C.T, Teles A.A.P. Surgical results from treating children with syndactyly through the collective effort system at "SOS Hand Recife" between 2005 and 2009. Rev. bras. ortop. vol.49 no.4 São Paulo July/Aug. 2014.

5. R.M. Jose, N. Timoney, R. Vidyadharan, R. Lester. Syndactyly correction: an aesthetic reconstruction. J Hand Surg, 35E (2010), pp. 446-450.

6. D.B. Lumenta, H.B. Kitzinger, H. Beck, M. Frey Longterm outcomes of web creep, scar quality, and function after simple syndactyly surgical treatment.J Hand Surg, 35A (2010), pp. 1323-1329.

7. M.D. Vekris, M.G. Lykissas, P.N. Soucacos, A.V. Korompilias, A.E. Beris. Congenital syndactyly: outcome of surgical treatment in 131 webs. Tech Hand Up Extrem Surg, 14 (2010), pp. 2-7.
Current techniques use zigzag incisions along the full length of the fingers and interdigital flaps to wrap the web space. Zigzag incisions show a lower rate of digital scar contracture than straight line closure. Cutaneous flaps, which can be dorsal, palmar, or both, do bring a skin of good quality, colour, and growth into the web compared with skin grafts. ${ }^{10,11,12}$ Separated digits, however, have a greater surface area than syndactylized digits and generally skin grafts are used to cover the raw areas, with some morbidity. ${ }^{11}$

The purpose of our study was to evaluate and study the different treatment options and types of syndactyly and their surgical outcomes ${ }^{13,14}$

Cortez et al; reported a series of 35 cases of syndactyly and concluded that varying degrees of surgical outcomes was noted in the simple and complex forms.

Lumenta et al; in his series of 26 affected web spaces who underwent surgery with palmar and dorsal skin flaps with zig-zag incisions for separation of digits. They reported a reduced incidence of web creep during their follow ups after surgery. ${ }^{15}$

In our case we presented two different types of syndactyly managed by two different techniques and the surgical outcome of both the patients at the end of four months was excellent.

8. T. Sugihara, T. Ohura, T. Umeda. Surgical method for treatment of syndactyly with osseous fusion of the distal phalanges. Plast Reconstr Surg, 87 (1991), pp. 157-164.

9. N.S. Niranjan, S.M . Azad, A.N. Fleming, S.H. Liew. Long-term results of primary syndactyly correction by the trilobed flap technique. Br J Plast Surg, 58 (1) (2005Jan), pp. 14-21.

10. ALH M oss, G. Foucher. Syndactyly: can web creep be avoided? J Hand Surg, 15B (1990), pp. 193-200.

11. J. Colville. Syndactyly correction. Br J Plast Surg, 42 (1989), pp. 12-16.

12. DT. Netscher. Congenital hand problems: technology, etiology, and managemenT.Clin Plast Surg, 25 (1998), pp. 537-552.

13. AE. Flatt. The care of congenital hand anomalies. (2nd ed), Quality Medical, St Louis (1994), pp. 228-275.

14. Sajid Malik. Syndactyly: phenotypes, genetics and current classification. European Journal of Human Genetics (2012) 20, 817-824.

15. Lumenta D.B, Kitzinger B.H, MD, Beck. H, MD, Frey M. Long-Term Outcomes of Web Creep, Scar Quality, and Function After Simple Syndactyly Surgical Treatment. 2010. Volume 35, Issue 8, Pages 1323-1329. 